\title{
POLÍTICAS COGNITIVAS NA FORMAÇÃO DO PROFESSOR E O PROBLEMA DO DEVIR-MESTRE
}

\author{
Virgínia Kastrup*
}

\begin{abstract}
RESUMO: O tema da aprendizagem ocupa na obra de Deleuze um lugar especial. A aprendizagem não é um processo de solução de problemas nem a aquisição de um saber, mas um processo de produção de subjetividade. Entendido a partir desta perspectiva, o problema da formação do professor surge ressignificado, envolvendo uma política cognitiva sintonizada com o entendimento da cognição como invenção de si e do mundo. Nessa medida, o conceito de devir-mestre indica um caminho para fazer face ao modelo de transmissão de informação baseado numa política de recognição.
\end{abstract}

Palavras-chave: Aprendizagem. Subjetividade. Devir-mestre. Formação de professores.

\section{COGNITIVE POLICIES IN TEACHER FORMATION AND THE PROBLEM OF THE BECOMING-TEACHER}

ABSTRACT: The theme of learning has a special in the work of Deleuze. For him, learning is neither a process for solving problems nor a process of knowledge acquisition, but rather a process of production of subjectivity. From this perspective, the issue of teacher training takes on new meanings, implying a cognitive policy that should be in harmony with a cognition conceived as an invention of the self and of the world. Bearing this in mind, the concept of becoming-teacher suggests a way, based a policy of recognition, to face the transmission of information model.

Key words: Learning. Subjectivity. Becoming-teacher. Teacher formation.

Doutora em psicologia pela Pontifícia Universidade Católica de São Paulo (PUC-SP) e pósdoutora no Centre National de la Recherche Scientifique (CNRS, França). E-mail: vkastrup@terra.com.br 


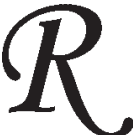
eunidos neste colóquio, colocamos problemas diversos, dependendo de nosso campo de atuação e de nosso próprio ponto de vista no interior deste campo. Vindo do campo da psicologia da cognição, o problema que eu gostaria de colocar diz respeito à formação do professor e à questão da aprendizagem, pois o modo como ela é entendida implica diretamente a maneira como concebemos o processo de ensino/aprendizagem. Pergunto então: Em que medida a filosofia de Gilles Deleuze, que cada vez mais demonstra sua potência de contágio e de fecundação de campos diversos, pode contribuir para o tratamento desses problemas no campo da educação? De que maneira o conceito de "devir", que introduz não apenas uma categoria que organiza um certo campo fenomenal, mas que possui uma dimensão política, concorre para o alargamento do conceito de "cognição"? E ainda: O que pode significar o conceito de devir-mestre? Meu objetivo é examinar algumas das implicaçôes para o campo da educação do que identifico como duas políticas distintas: a política da recognição e a política da invenção (Kastrup, 1999). Pretendo também discutir possíveis contribuições do conceito de "aprendizagem inventiva" para o enfrentar problemas que dizem respeito ao trabalho da educação na contemporaneidade.

De saída, é preciso dizer que a invenção não se confunde com a criatividade. Os estudos acerca da criatividade, iniciados nos EUA por J. P. Guilford e que ganharam força sobretudo na década de 1960, definem a criatividade como uma capacidade de produzir soluçôes originais para os problemas. Mas a invenção de que eu falo, e para isso me baseio na filosofia de G. Deleuze (1988), não é uma capacidade de solução de problemas mas, sobretudo, de invenção de problemas. Além disso, a invenção é sempre invenção do novo, sendo dotada de uma imprevisibilidade que impede sua investigação e o tratamento no interior de um quadro de leis e princípios invariantes da cognição. A própria idéia de uma teoria da invenção, nos moldes da ciência moderna, é uma contradição de termos (Stengers, 1993). Pois se houvesse uma teoria da invenção, ou mesmo leis da invenção, seus resultados seriam passíveis de previsão, o que trairia o caráter de novidade e imprevisibilidade que toda invenção comporta.

Fazer da invenção um problema significa recusar a invariância das condiçôes de possibilidade da cognição e reconhecer seu caráter temporal e de diferenciação interna. A invenção é uma potência que a cognição tem de diferir de si mesma. Ela não é um processo psicológico a mais, além da percepção, do pensamento, da aprendizagem, da memória ou 
da linguagem, mas é uma potência temporal, potência de diferenciação, que perpassa todos os processos psicológicos. Colocando o problema da cognição a partir da invenção, falaremos então de uma percepção inventiva, de uma memória inventiva, de uma linguagem inventiva e - o que é de particular interesse aqui - de uma aprendizagem inventiva.

Cabe ainda ressaltar que a invenção não é um processo que possa ser atribuído a um sujeito. A invenção não deve ser entendida a partir do inventor. $\mathrm{O}$ sujeito, bem como o objeto, são efeitos, resultados do processo de invenção. Este modo de pensar encontra ressonância na obra de Francisco Varela, e está presente desde a formulação da teoria da autopoiese, na ocasião de sua parceria com Humberto Maturana. Já nessa época é a ação, o fazer, a prática cognitiva que configura o sujeito e o objeto, o si e o mundo. A transformação temporal da cognição não segue um caminho necessário, não leva a uma seqüência de estruturas cognitivas e estágios que seguiriam uma ordem invariante, como nas teorias do desenvolvimento cognitivo, mas é antes uma deriva, criada a partir dos acoplamentos com as forças do mundo.

Esta maneira de entender a cognição se distingue da abordagem cognitivista, que foi por várias décadas dominante neste campo de investigação. De acordo com essa abordagem, a cognição é uma relação entre um sujeito e um objeto, constituindo um espaço de representação. Além de pressupor sujeito e objeto como pólos prévios ao processo de conhecer, a concepção da cognição como representação traz consigo a preocupação com a busca de leis e princípios invariantes, que funcionariam como condições de possibilidade do funcionamento cognitivo. $\mathrm{O}$ modelo da representação caracteriza sistemas psicológicos diversos, como a psicologia da gestalt, a psicologia genética de J. Piaget, bem como o cognitivismo computacional que surge no campo das ciências cognitivas. No caso deste último, o que prevalece é o entendimento da cognição como processamento de informação. O sistema cognitivo recebe inputs, realiza seu processamento de acordo com regras lógicas e transforma-os em outputs. Varela afirma que o cognitivismo computacional trabalha com o modelo do tubo: input - processamento simbólico - output. Resulta daí uma concepção lógica da cognição, o que significa seu resfriamento formal. Ela se limita a um processo de solução de problemas, sem espaço para a invenção de problemas. As informações chegam de um mundo preexistente e o sistema cognitivo opera com regras e representações, chegando a resultados previsíveis. 
Para Varela, ao contrário, o sujeito e o objeto, o si e o mundo são efeitos da própria prática cognitiva. $\mathrm{O}$ mundo perturba, mas não informa. O conceito de "perturbação" ou de "breakdown" responde pelo momento da invenção de problemas, que é uma rachadura, um abalo, uma bifurcação no fluxo recognitivo habitual. O conceito de "breakdown" é essencial na argumentação de que não existe mundo prévio, nem sujeito preexistente. $\mathrm{O}$ si e o mundo são co-engendrados pela ação, de modo recíproco e indissociável. Encontram-se, por sua vez, mergulhados num processo de transformação permanente. Pois ainda que sejam configurados como formas, estas restam sujeitas a novas perturbações, que forçam sua reinvenção. Como tenho procurado demonstrar (Kastrup, 1995, 1999, 2000, 2001, 2001-2002), este modo de entender a cognição encontra ressonância nos estudos da produção da subjetividade de Deleuze e Guattari. Neste contexto, subjetividade e objetividade não são entidades preexistentes, mas efeitos de agenciamentos coletivos. Os processos de subjetivação e de objetivação fazem-se num plano aquém das formas, plano de forças moventes que, por seu agenciamento, vêm a configurar formas sempre precárias e passíveis de transformação. As formas distinguemse, mas não se separam do plano de forças de onde elas emergem, permanecendo nele imersas por meio de uma zona de adjacência. $\mathrm{O}$ conceito de "devir" procura dar conta de um movimento involutivo (Deleuze \& Guattari, 1997), que opera um desmanchamento das formas, relançando-as no plano das forças informes. Nesta medida, o devir corresponde a um momento de dessubjetivação, que é condição para que o processo de produção de subjetividade se mantenha em curso. É preciso sublinhar que a novidade do conceito de "subjetividade" é ser indissociável da noção de produção. Caso contrário, falar de subjetividade e não de sujeito seria apenas uma mudança de nomenclatura, sem qualquer novidade conceitual. É também preciso notar que o conceito de "subjetividade" se refere a duas coisas. Em primeiro lugar, ao processo de produção; em segundo, às formas que resultam desse processo, que são os seus produtos. Trata-se aí dos dois planos a que me referi anteriormente. Planos que são distintos, embora indissociáveis: o plano dos processos e das forças moventes e o plano das formas que dele emergem. Estas duas inflexôes do conceito de "subjetividade" marcam também a noção de invenção, que caracteriza, ao mesmo tempo, o processo de inventar e o invento que dele resulta. Conforme veremos adiante, são dois planos indissociáveis, mas as formas inventadas podem manter um contato mais ou menos próximo, mais ou menos aberto ao plano de forças de onde elas advêm. 
Depois desta introdução, que dá as principais diretrizes e os balizamentos para a correta colocação do problema da invenção, vou me deter um pouco mais no exame do problema da aprendizagem. Meu objetivo será explorar algumas das implicações de pensar a aprendizagem a partir da invenção. No campo da psicologia tradicional, o debate concentrou-se prioritariamente na polêmica entre o caráter mecânico ou inteligente da aprendizagem, representado pelas concepções behavioristas e gestaltistas. No contexto contemporâneo, a teoria da autopoiese, a abordagem conexionista da cognição e os estudos acerca da produção da subjetividade de G. Deleuze e F. Guattari abrem a possibilidade de colocar diferentemente o problema, indicando uma terceira via, que eu venho chamando de "aprendizagem inventiva". A aprendizagem surge como processo de produção da subjetividade, como invenção de si. Além disso, a invenção de si tem como correlato, simultâneo e recíproco, a invenção do próprio mundo. $\mathrm{O}$ estudo da aprendizagem desvia-se então da perspectiva ambientalista, que se encontra presente, explícita ou implicitamente, nas concepçóes que restringem a aprendizagem a um processo de solução de problemas (Kastrup, 2001-2002). Perspectivada pela invenção, a aprendizagem surge como processo de invenção de problemas. Aprender é, então, em seu sentido primordial, ser capaz de problematizar a partir do contato com uma matéria fluida, portadora de diferença e que não se confunde com o mundo dos objetos e das formas.

A noção de aprendizagem inventiva inclui então a invenção de problemas e revela-se também como invenção de mundo. Trata-se de dotar a aprendizagem da potência de invenção e de novidade. Tomemos como exemplo a experiência com a arte, evocando Varela quando aborda o problema da aquisição da habilidade musical. A aprendizagem de tocar um instrumento revela uma dimensão que ultrapassa aquela de solução de problemas e de adaptação a um mundo preexistente, indicando a invenção recíproca e indissociável de si e do mundo como, no caso, do músico e da música (Varela, Thompson \& Rosch, 1993). Aprender resta sendo antes uma questão de invenção que de adaptação. A referência à experiência estética serve também para revelar o exercício de uma atenção distinta daquela envolvida na realização de tarefas. A arte mobiliza e desenvolve, em sua aprendizagem, uma atitude atencional que é, ao mesmo tempo, concentrada e aberta (Depraz, Varela \& Vermersch, 2003). A aprendizagem da música envolve não apenas tocar, reger e compor, mas também o tornar-se mais sensível para ouvir música, deixando-se tocar por ela em toda a sua força (idem, ibid., p. 99). Fica claro aqui que a 
habilidade musical não é meramente técnica, nem visa a um adestramento muscular e mecânico. Está envolvida aí uma aprendizagem da sensibilidade, o que significa a aprendizagem de uma atenção especial que encontra a música, deixando-se afetar por ela e acolhendo seus efeitos sobre si. Depraz, Varela \& Vermersch (2003) destacam na música a sua dimensão de força afectiva, que devemos interpretar como sua dimensão não-recognitiva. É na qualidade de força que a música surge como novidade, produzindo surpresa e instalando um estado de exceção, de breakdown, de suspensão do tempo.

A novidade e a surpresa configuram uma das faces da dupla temporalidade da aprendizagem. A segunda face de sua temporalidade é a sedimentação e o enraizamento. A sedimentação do aprendizado ocorre por intermédio da repetição e do ritmo de um treino que se dá por meio de um conjunto de sessóes consecutivas e regulares. O sentido do treino é criar um campo estável de sedimentação e acolhimento de experiências afectivas inesperadas, que fogem ao controle do eu. A regularidade das sessões tem como efeito a criação de uma familiaridade com as experiências de breakdown e, enfim, o desenvolvimento de uma atitude cognitiva e atencional ao plano das forças. O processo começa com esforço, por intermédio de uma atitude consciente e intencional, mas que se torna, com a prática, espontânea e inintencional.

A aprendizagem é entendida como cultivo, o que procura ressaltar que ela resulta no aumento da força e da potência que já existe na cognição. Depraz, Varela \& Vermersch afirmam: "Cantores não precisam criar seu aparato vocal, mas sim, sobre a base deste aparato, um instrumento perito que lhes permite cantar" (2003, p. 100). "Pianistas não precisam construir mãos para tocar, mas levam anos e anos criando mãos de pianistas: fortes, destras, calibradas no espaço, com uma extraordinária precisão" (idem, ibid.). Com o intuito de ressaltar a questão do enraizamento da aprendizagem, a idéia de que o aprendizado se faz sobre o corpo afirma que "não envolve invenção". Constata-se então que a noção de invenção da qual procuram demarcar-se é a invenção ex-nihilo, que cria o novo a partir do nada (Kastrup, 1999). Entretanto, quando falamos em invenção recorremos a sua etimologia latina - invenire -, que significa compor com restos arqueológicos. Inventar é garimpar algo que restava escondido, oculto, mas que, após serem removidas as camadas históricas que o encobriam, revela-se como já estando lá. As mãos do pianista não são uma invenção ex-nihilo nem se definem por seu aparato bi- 
ológico. Definem-se pela destreza, firmeza, precisão e perícia no movimento dos dedos, que são cuidadosamente produzidas. A capacidade de desenvolver movimentos tão finos e precisos existia como virtualidade, mas precisou ser cultivada por meio do ritmo de uma prática repetida. O corpo biológico surge como esta reserva de virtualidade, o mesmo valendo para a atenção às forças.

A noção de cultivo embaralha a lógica linear do aprendizado, pautando-se na idéia de que "sempre se está à frente de si mesmo". O aprendizado por cultivo é um processo de atualização de uma virtualidade, ganhando o sentido de diferenciação. Trata-se de ativar gestos, aumentando sua força por meio do exercício e do treino. O problema do tempo do treino é relevante aí, tanto no sentido do aumento da potência do gesto cognitivo quanto para a produção de um sentido de apropriação desse gesto, do fazê-lo seu. O novo e o antigo, o que surge e o que já estava lá, não são pares antinômicos, mas se ligam por uma linha de repetição, diferenciação e invenção.

A cognição inventiva não é o mesmo que cognição espontânea. Embora a invenção não seja privilégio de grandes artistas ou cientistas, mas seja distribuída por todos e por cada um, ela depende de cultivo. A invenção não vai por si, mas envolve repetição. $\mathrm{O}$ aprendizado depende, de saída, da suspensão da atitude recognitiva. Começando por mobilizar uma intenção consciente, torna-se aos poucos inintencional. Depraz, Varela \& Vermersch apontam que, no longo prazo, uma segunda espontaneidade tem lugar. Esta é definida com a curiosa formulação de um esforço sem esforço, que supera tanto a dicotomia ativo/passivo quanto a dicotomia voluntário/involuntário. Nesta segunda espontaneidade a atenção não é ativa, pilotada por um eu, nem passiva, lançada reflexa ou mecanicamente ao sabor dos estímulos do ambiente externo. Partindo da suspensão da recognição, o aprendizado estabiliza um tônus atencional singular que envolve a ativação de uma atenção aberta ao encontro de experiências pré-egóicas. Esta atenção se encontra até certo ponto desativada, sendo pouco investida na contemporaneidade. Aumentar sua potência e trabalhar para sua estabilização por intermédio de práticas de transformação de si é atualizar uma virtualidade por meio da aliança da surpresa com a regularidade.

O aprendizado assume a forma de um círculo, em que o movimento é o de reincidir, retornar, renovar, reinventar, reiterar, recomeçar. Em última análise, a lógica circular do aprender aponta para o 
inacabamento do processo. O aprendizado jamais é concluído e sempre abre para um novo aprendizado. Ele é contínuo e permanente, não se fechando numa solução e não se totalizando em sua atualização, precisando por isso ser sempre reativado.

Num outro contexto, mas numa mesma direção, Deleuze (1988) insistiu na importância da categoria de problema para fazer face à imagem dogmática do pensamento, pautada na representação e na recognição, apontando o limite da abordagem psicológica, restrita ao âmbito da solução de problemas. Para Deleuze a invenção do problema porta um caráter de necessidade, não sendo um processo subjetivo de compreensão de uma situação. Como afirmará mais tarde (Deleuze, 1987), são os signos que fazem problema e que forçam a pensar. Em Proust e os signos (1987), afirma: a arte é o destino inconsciente do aprendiz. A arte surge como uma perspectiva, como um ponto de vista a partir do qual a aprendizagem vai ser concebida. Entendida sob a perspectiva da arte, a aprendizagem possui características que não foram consideradas no âmbito da psicologia tradicional. De saída, o desempenho de uma atividade artística como tocar um instrumento, pintar um quadro ou escrever um poema não se enquadra no modelo de adaptação ao mundo externo. O aprendizado de uma arte não se submete aos parâmetros da solução de problemas e da adaptação, mas envolve uma aprendizagem permanentemente criadora e um direito ao inacabamento que é sua marca. $\mathrm{O}$ aprendizado da arte não se esgota na aquisição de respostas e de regras cognitivas. $\mathrm{O}$ aprendiz-artista não é aquele que repete mecanicamente uma mesma resposta ou uma regra definida, mas aquele que é capaz de reinventar-se permanentemente, inventando simultaneamente novos mundos. A aprendizagem da arte desenvolve-se numa tensão permanente entre a invenção de problemas e a solução de problemas. O direito ao inacabamento aponta para um processo de aprendizagem permanente, mas também de desaprendizagem permanente, pois o verdadeiro artista é aquele que jamais abandona sua condição de aprendiz.

\section{As políticas cognitivas e o devir-mestre}

No entanto, considero que o problema da cognição não se esgota na questão de sua estrutura e funcionamento. É preciso colocar o problema das políticas cognitivas e interrogar: Que tipo de relação se estabelece com a cognição? E aí não estamos limitados a uma questão de mode- 
los teóricos, mas ao modo como a cognição se configura em formas concretas. É certo que a correta colocação do problema é fundamental. Pois somente entendendo a cognição como invenção podemos dar conta do fato de que algumas formas cognitivas, forjadas pelas nossas práticas concretas, resultam em subjetividades que encarnam o funcionamento inventivo, e outras resultam em subjetividades recognitivas, que se limitam a tomar o mundo como oferecendo informações prontas para serem captadas. As primeiras, que encarnam a política de invenção, exercitam a problematização, são afetadas pela novidade trazida pela experiência presente e tomam o conhecimento como invenção de si e do mundo. Ainda que as práticas cognitivas configurem regras, estas são tomadas como temporárias e passíveis de reinvenção. O segundo tipo de política, a de recognição, polariza-se em duas posiçôes. A primeira evidencia uma atitude realista, que faz com que lidemos com o mundo como se ele preexistisse. A segunda é a atitude idealista e individualista. Agimos como se tivéssemos um eu, como se fôssemos o centro, a fonte e o piloto do processo de conhecimento. O que prevalece é a crença de que o conhecimento é configurado pelos esquemas recognitivos, pelas regras e pelo saber anterior. Seja fundamentando o conhecimento nas formas de um mundo preexistente, seja na forma do sujeito cognoscente, a atitude realista e a idealista/individualista apresentam-se como duas faces da mesma política da recognição, que toma o conhecimento como uma questão de representação.

Como estamos sempre sujeitos ao esquecimento das condições de emergência do si e do mundo e de sua natureza processual, a política de invenção deve ser exercitada por intermédio de práticas concretas e de um constante processo de aprendizagem. É preciso, por meio desse processo, reconquistar permanentemente o acesso da cognição ao plano processual das forças moventes. As práticas de aprendizagem inventiva constituem um caminho para expurgar o cognitivista que existe em nós e que nos habita, muitas vezes de maneira clandestina, assombrando-nos com o modelo da representação.

Ainda nesta direção, cabe perguntar também sobre o tipo de relação que se estabelece com a aprendizagem. De acordo com a política da recognição, aprende-se para obter um saber. A aprendizagem é solução de problemas preexistentes, que são colocados muitas vezes pelo professor. A atenção que é mobilizada durante o processo de aprendizagem atém-se a formas prontas e à aquisição de informações. Já na política de 
invenção, a aprendizagem inclui a experiência de problematização e a invenção de problemas. A aprendizagem não se submete a seus resultados, mas faz bifurcar a cognição, mantendo acessível seu funcionamento divergente. Aprender é, então, fazer a cognição diferenciar-se permanentemente de si mesma, engendrando, a partir daí, novos mundos. A política da invenção é, assim, uma política de abertura da atenção às experiências não-recognitivas e ao devir. O desafio da implementação dessa política é conceber práticas que viabilizem o desencadeamento de processos de problematização que não se esgotem ao encontrar uma solução.

Trazendo o problema para o âmbito das práticas pedagógicas, cabe destacar que o problema da atenção tem tido lugar de destaque na escola contemporânea. Um dos motivos é que o funcionamento da atenção de grande parte das crianças e jovens vem assumindo hoje em dia uma característica de dispersão. Ela desliza incessantemente entre fatos e situações, transparecendo uma certa dificuldade de concentração. Numa busca acelerada por novidades, a atenção é passageira, muda constantemente de foco e está sujeita ao esgotamento em frações de segundo. Quando se procura descrever como a atenção funciona nos dias atuais, o primeiro aspecto que sobressai é uma acentuada dispersão, que resulta da mudança constante do foco da atenção. Não é difícil perceber que alguns fatores participam da produção desse tipo de subjetividade. As imagens e os textos constantemente veiculados pela mídia, bem como a explosão recente das tecnologias da informação, tornam disponível uma avalanche de informações, atravessando grandes distâncias em alguns segundos. Por sua vez, os celulares são também fatores importantes, atravessando sem cessar o fluxo da vida cotidiana. Observa-se que há neste quadro de coisas algo que é da ordem da quantidade. Há na sociedade contemporânea um excesso de informação e uma velocidade acelerada que convoca uma mudança constante do foco da atenção, em função dos apelos que se multiplicam sem cessar.

É cada vez mais freqüente o diagnóstico de transtorno de déficit de atenção (TDA), que tem como sintomas baixo rendimento na realização de tarefas, dificuldade de seguir regras e desenvolver projetos de longo prazo, e a cujo quadro podem estar associadas a hiperatividade e a impulsividade. No contexto escolar, o problema é colocado como aquele da atenção requerida para que o processo de aprendizagem tenha lugar. Considera-se que a criança não aprende porque não presta atenção. Esse funcionamento disperso da atenção na subjetividade contemporânea não 
é tratado como um problema de ordem moral, sendo antes tomado como um transtorno que exige tratamento (Crary, 2001). Muitas crianças são encaminhadas para terapias cognitivas, que têm em vista aumentar a capacidade de atenção para a realização de tarefas. $\mathrm{O}$ que prevalece nesse domínio é o entendimento da cognição como processo de solução de problemas e, no que diz respeito à atenção, a ênfase recai sobre seu papel no controle do comportamento e na realização de tarefas. Ela é a condição para que se desenvolva o processo de aprendizagem, a solução de problemas e o desempenho de tarefas cognitivas. Tomada como uma espécie de processo subsidiário à aprendizagem e estando a seu serviço, sua análise é restrita à atenção voltada para objetos e estímulos do mundo externo, ou seja, para a captação e a busca de informações. A falha no trato com as informações externas é sinal de pouca atenção e baixa capacidade de concentração. Tendo em vista que a noção de cognição é restrita à solução de problemas e que a proposta clínica é declaradamente adaptativa, a questão é como restabelecer a capacidade de prestar atenção, ou seja, como promover a aprendizagem de uma atenção que é necessária à realização de tarefas.

A noção de déficit indica que subjaz aí um entendimento da atenção como marcada por um funcionamento binário: $0-1$, atençãodesatenção. Tudo aquilo que escapa ao ato de prestar atenção fica alocado na rubrica do negativo, da falta, do déficit. Ao procurar fazer frente ao funcionamento da atenção que foge da tarefa, são igualmente consideradas indesejáveis a dispersão e a distração. No entanto, os fenômenos são distintos. A dispersão consiste num repetido deslocamento do foco atencional, que impossibilita a concentração, a duração e a consistência da experiência. Um exemplo é a pessoa que tenta assistir à televisão, mas passa a noite inteira "zapeando" os canais, agarrada ao controle remoto que a conduz de um programa a outro. Ao final da noite ela sabe quais os programas que passaram na TV, embora de fato não tenha assistido a nenhum deles. Uma certa avidez de novidade impede a espessura temporal e a consistência da experiência. Já a distração é um funcionamento em que a atenção vagueia, experimenta uma errância, fugindo do foco da tarefa para a qual é solicitado prestar atenção e indo na direção de um campo mais amplo, habitado por pensamentos fora de lugar, percepçóes sem finalidade, reminiscências vagas, objetos desfocados e idéias fluidas, que advêm do mundo interior ou exterior, mas que têm em comum o fato de serem refratárias ao apelo da tarefa em questão. É curioso notar 
que o distraído é alguém extremamente concentrado, que não é meramente desatento, mas cuja atenção se encontra em outro lugar. Cabe sublinhar ainda que diversos autores considerem que o TDA seja em parte causado pelas características da sociedade atual (além da predisposição genética); ele é tratado como um problema individual, aliando técnicas comportamentais e medicamentos como a ritalina (metilfenidato).

No que diz respeito às açóes da escola, é interessante notar que tem sido comum hoje em dia o discurso de que esta deve repensar seus objetivos, tendo em vista que a criança não vê sentido nem utilidade imediata para o tipo de conhecimento que a escola transmite. Afirma-se que as informações hoje em dia são numerosas e descartáveis, possuindo vida curta. Seguindo este raciocínio, o mais importante seria então capacitar a criança para dominar as novas tecnologias da informação e desenvolver mecanismos e capacidades de busca por novas informações, que proliferam a cada dia. O computador ocupa lugar central em tal discussão. A questão é como fazer a criança aprender a utilizá-lo e, sobretudo, a acessar a internet para dispor de informaçóes em quantidade e em tempo real. Se a criança estiver sintonizada com a avalanche de informações do mundo contemporâneo, o êxito de sua educação estará em grande parte garantido.

Mas parece-me que, com este encaminhamento do problema substituição do professor pela máquina e do saber cristalizado pela informação de curto prazo -, mantém-se o tradicional projeto pedagógico baseado no modelo de transmissão de informação. Trata-se apenas de uma versão high tech da política de recognição. A importância conferida ao desenvolvimento de uma competência para a busca de informaçôes novas não chega a problematizar o que seja conhecer, nem garante uma nova política cognitiva. Ao contrário, esse tipo de estratégia apenas reforça o sentimento de que estamos sempre em déficit, jamais conseguindo dar conta da avalanche de informações que nos atinge nos dias atuais.

É importante ressaltar que os movimentos frenéticos de busca na internet não constituem devires. O devir não é um movimento sensóriomotor. Ao contrário, o excesso de movimentos sensório-motores afasta devires, fazendo com que a cognição "zapeie" em meio a formas prontas, num funcionamento homogêneo e restrito ao plano das formas. Os devires são experiências novas, inéditas, que nos colocam em contato com a alteridade do mundo e da própria cognição. É neste sentido que o devir é dito involutivo. Ele envolve a atenção ao plano das forças, provocando 
experiências de problematização, de estranhamento e produzindo bifurcação no fluxo recognitivo habitual. Não se trata de maldizer as novas tecnologias, mas de apontar que, se seu uso está a serviço do desempenho de tarefas predefinidas e da solução de problemas dados, elas nada mudam em termos de política cognitiva. Ao contrário, elas podem servir ao recrudescimento da política de recognição, que separa a cognição da invenção. O problema da dispersão da atenção que atinge crianças, jovens e adultos na contemporaneidade deve ser enfrentado por meio de práticas capazes de colocar em questão a suposta identificação entre conhecimento e informação.

O que seria uma prática pedagógica capaz de produzir uma política cognitiva da invenção, deslocando o foco da informação para a problematização? Em que consistiria manter viva a atenção ao plano de forças e dos devires, a potência de resistência à recognição? E, ainda, como expressar a potência do abalo, das dissonâncias e da bifurcação que uma certa prática pedagógica pode produzir na subjetividade? Pois para ser mestre não basta transmitir informações novas, que logo serão substituídas por novas informaçôes novas e igualmente descartáveis, mas produzir uma experiência nova, que não envelhece, que conserva sua força disruptiva e se mantém sempre nova.

Diante dessas questôes, reporto-me a um texto de Deleuze que tem o título "Il a été mon maître". Trata-se de um texto publicado em 1964, pouco depois de Sartre ter recusado o Prêmio Nobel, para o qual havia sido indicado. Essa recusa provocou uma grande polêmica no meio intelectual francês, o que parece ter levado Deleuze a manifestar-se publicamente sobre o caso. Após caracterizar Sartre como um intelectual que exerceu sua atividade fora do circuito universitário público francês, afirma que ninguém como ele conseguiu dizer alguma coisa nova e por isso ensinar uma nova maneira de pensar. Fazendo um balanço de sua formação, afirma que só quando se chega à idade adulta nos damos conta de que nossos verdadeiros mestres foram aqueles que nos marcaram por meio de sua radical novidade na maneira de pensar, que foram capazes de tocar, ao mesmo tempo, nossas dificuldades e nosso entusiasmo. Deleuze localiza aí, numa espécie de verdade de primeira mão, a autêntica novidade daquilo que diz um professor e que vem sempre por intermédio de um determinado estilo. $\mathrm{O}$ de Sartre era um estilo polêmico e mesmo agressivo de colocar os problemas e foi por meio dele que ele inventou algo novo: a ligação do pensamento com a liberdade. Descreven- 
do Sartre, Deleuze afirma: "Toda sua filosofia se inseria num movimento especulativo que contestava a noção de representação, a ordem mesma da representação: a filosofia mudava de lugar, saía da esfera do julgamento, para se instalar no mundo mais colorido do pré-judicativo, do sub-representativo. Sartre acaba de recusar o Prêmio Nobel. Continuação prática da mesma atitude, do horror de representar praticamente qualquer coisa, sejam eles valores institucionais ou, como ele diz, o ser institucionalizado" (Deleuze, 2002, p. 110-111). Ao contrário da maioria, Deleuze toma a recusa de Sartre à premiação como uma boa notícia, reafirmando a vocação e o destino deste professor e pensador para "fazer passar ar puro quando fala, mesmo quando esse ar puro, o ar das ausências, é difícil de respirar" (idem, ibid., p. 113). Esse belo texto, do qual recortei alguns fragmentos, ajuda a entender o que denominei de política cognitiva da invenção de si e do mundo. Deixando patente que o conhecimento não se separa da política, Deleuze aponta como nossos mestres deixam em nós sua marca, sua política cognitiva. Foi a liberdade de Sartre, sua coragem de colocar novos problemas, de pensar diferentemente e de surpreender sempre que fizeram dele um verdadeiro mestre. Pode-se dizer que o estilo-Sartre de mestria foi forjado por meio da repetição diferencial, e ao mesmo tempo coerente, da problematização. E que foi justamente por intermédio de tais experiências de problematização, as quais foram capazes de afetar profundamente seus alunos, que ele atualizou um devir-mestre.

Ainda com relação ao problema do devir-mestre, remeto a uma colocação de Deleuze nas entrevistas que deu a Claire Parnet e que saíram publicadas no L'abécédaire (s/d.). A letra P é dedicada a "Professor" e Deleuze faz, a este respeito, colocações muito interessantes. Afirma que não gosta de dar conferências, mas prefere os cursos com aulas consecutivas. Considera que esta é uma condição melhor para o trabalho do professor, pois as aulas são blocos de espaço-tempo sucessivos, configurando um campo mais amplo que o limite espaciotemporal da conferência. As aulas introduzem ao processo de ensino o que chamamos de um ritmo. Ainda com relação ao ritmo, é interessante notar que Deleuze descreve de forma bem curiosa seu processo de preparação dos cursos. Afirma que é preciso muito preparo, muita repetição, para conseguir alguns poucos minutos de inspiraçãa. Sugerindo que a inspiração é o momento em que o problema surge, em que se tem uma idéia, que é um movimento de devir da cognição, fica marcado o esforço que ele pode envolver. Esforço que Deleuze considera indispensável para sua atividade de professor. O 
ritmo do preparo de um curso envolve um processo de aprendizagem inventiva. Em contrapartida, o encontro entre professor e aluno, a chamada relação ensino/aprendizagem, faz-se no coração das experiências de devir, onde o novo é experimentado. É no encontro no plano das forças, na potência de propagação de experiências não-recognitivas, que pode ser flagrado o devir-mestre.

Concluo afirmando que o devir-mestre não consiste num tornarse mestre. Não há uma forma-mestre, mas momentos em que as subjetividades do professor e do aluno se encontram. Por isso insisto que a discussão sobre a formação do professor não pode abrir mão da questão da política cognitiva que praticamos. Política que implica a ultrapassagem de nossa atitude recognitiva e que exige uma luta permanente contra o cognitivista que insiste em se instalar em nós. No campo da invenção, nada está garantido. Nada é desde sempre nem para sempre. Também não há um método único nem receitas infalíveis. O desafio não é capturar a atenção do aluno para que ele aprenda, mas promover nosso próprio aprendizado da atenção às forças do presente, que trazem o novo em seu caráter disruptivo. Pois ensinar é, em grande parte, compartilhar experiências de problematização. Estas podem ser fugazes, emergindo no campo da percepção e se dissipando em seguida. Mas é imprescindível a manutenção de sua potência para a invenção de novas subjetividades e de novos mundos. Por isso considero que, no domínio da formação, é preciso encontrar estratégias de constante desmanchamento da tendência a ocupar o lugar do professor que transmite um saber. Penso que não se trata de determinismo nem de livre arbítrio; nem de submissão a um modelo existente, nem de boa vontade. O caminho é de um aprendizado permanente. Trata-se de um processo lento, marcado por idas e vindas, mas só ele possibilita a criação de uma política cognitiva da invenção.

Recebido em maio de 2005 e aprovado em julho de 2005.

Referências bibliográficas

CRARY, J. Suspensions of perception. Cambridge, Mass.: MIT, 2001.

DELEUZE, G. Proust e os signos. Rio de Janeiro: Forense Universitária, 1987. 
DELEUZE, G. Diferença e repetição. Rio de Janeiro: Graal, 1988.

DELEUZE, G. L'̂̀le déserte et autres textes. Paris: Minuit, 2002.

DELEUZE, G. L'abécédaire de Gilles Deleuze: entrevistas com Claire Parnet. Realização de P.-A. Boutang. Paris: Montparnasse ; Liberation, [s/d.].

DELEUZE, G.; GUATTARI, F. Mil platôs. Rio de Janeiro: Editora 34, 1997. v.4

DEPRAZ, N.; VARELA, F.; VERMERSCH, P. (Ed.). On becoming aware: a pragmatic of experiencing. Amsterdam; Philadelphia: J. Benjamins, 2003.

KASTRUP, V. Autopoiese e subjetividade: sobre o uso da noção de autopoiese por G. Deleuze e F. Guattari. Revista do Departamento de Psicologia da UFF, Niterói, v. 7, n. 1, p. 96-97, 1995.

KASTRUP, V. A invenção de si e do mundo. Campinas: Papirus, 1999.

KASTRUP, V. O devir-criança e a cognição contemporânea. Psicologia: reflexão e crítica, Porto Alegre, v. 13, n. 3, p. 373-382, 2000.

KASTRUP, V. Aprendizagem, arte e invenção. In: Lins, D. (Org.). Nietzsche e Deleuze: pensamento nômade. Rio de Janeiro: RelumeDumará; Fortaleza: Secretaria de Cultura e Desporto do Estado, 2001.

KASTRUP, V. Produção da subjetividade na era da informática e a questão do ambientalismo. Redes, n. 12-13, p. 27-42, 2001-2002. (Documenta)

STENGERS, I. L'invention des sciences modernes. Paris: La Découverte, 1993.

VARELA, F.; THOMPSON, E.; ROSCH, E. L'inscription corporelle de l'esprit. Paris: Seuil, 1993. 